\title{
TESTIGO Y PROTAGONISTA. UN DIARIO \\ DE PROVINCIA EN LA CONSTRUCCIÓN \\ DEL CAMPO DE LO POLÍTICO. \\ EL LITORAL, SANTA FE, 1918-1966
}

DARÍO MACOR

Ponencia escrita para las XIV Jornadas Interescuelas

/ Departamentos de Historia. Universidad Nacional

de Cuyo, realizadas en Mendoza del 2 al 5 de oc-

tubre de 2013.

\section{I}

En las últimas décadas un conjunto importante de trabajos ha complejizado de manera notable el pacto de lectura de la prensa escrita en las Ciencias Sociales ${ }^{1}$. En ese marco, y a fin de situar en esa complejidad nuestro objeto de interés -esto es el diario El Litoral de la ciudad de Santa Fe-, organizaremos en estos primeros párrafos algunas reflexiones sobre los diarios y la prensa escrita en general que son una especie de producto derivado del oficio de historiador. Esas notas, nunca reproducidas en un texto, en torno a las cuales uno va construyendo un diálogo con el objeto de estudio y con la fuente de acceso; un diálogo mediado por un vínculo singular: el que establecemos con una voz del pasado a la que interpelamos para transformar a ese pasado en historia.

El Litoral que aquí nos interesa es un diario de época, del corto siglo veinte que para nosotros se inaugura en el clima de la primera guerra mundial (1914) y la democratización política argentina (1912-1916). En el recorte aquí realizado, que

${ }^{1}$ Entre los numerosos trabajos pueden citarse: Tim Duncan, «La prensa política: Sud-América» en: Gustavo Ferrari y Ezequiel Gallo: La Argentina del 80 al Centenario, Buenos Aires, Sudamericana, 1980; Ricardo Sidicaro, La política mirada desde arriba. Las ideas del diario La Nación, 1909-1989, Buenos Aires, Sudamericana, 1993; Eduardo Zimmermann, «La prensa y la oposición política en la Argentina de comienzos de siglo", en; Estudios Sociales, n 15, 1998; Sylvia Saitta, Regueros de Tinta, El diario Crítica en la década de 1920, Buenos Aires, Sudamérica, 1998; Paula Alonso (ed.), Construcciones impresas. Panfletos, diarios y revistas en la construcción de los estados nacionales de América Latina, Buenos Aires, FCE, 2004. Leonardo Hirsch: «Prensa independiente y crítica moral al juarismo (1889-1890)», en: Estudios Sociales, n 40, Santa Fe, 2013. 
se extiende hasta los años sesenta, hay un período fundacional de vital importancia para el diario que nos ocupa: los años veinte, treinta y comienzos de los cuarenta, cuando construye una tradición que será decisiva para su identidad como principal órgano de prensa de una ciudad capital de provincia y su zona de influencia (centro norte de la provincia). Fue en esos años, marcados por las dos guerras mundiales, cuando el diario construyó una tradición que explica en mucho su capacidad de sobrevivencia como protagonista y testigo de esta sociedad.

Quisiéramos subrayar esta cuestión: la emergencia de una tradición en esas décadas fundacionales es una marca de origen imposible de disimular, en las décadas posteriores y todavía hoy, cuando los imperativos del mundo comunicacional son tan diferentes; aún hoy cuando aquella Argentina de la primera mitad del siglo $\mathrm{XX}$ en la que el diario buscaba un lugar como protagonista de relevancia ya no existe. Aún hoy, los diálogos con esa tradición pueden encontrarse en las páginas contemporáneas del diario, con una frecuencia que podría sorprender a sus mismos protagonistas; aún hoy, sus periodistas celebran la hora de cierre diaria cuando la mayoría de sus colegas nacionales están comenzando sus tareas en las redacciones; aún hoy, El Litoral insiste con éxito en pautar el ritual comunicacional con sus lectores en la tranquilidad del atardecer.

Como sabemos, la noción de tradición hace referencia a una continuidad de sentido, a una transmisión de saberes y prácticas de una generación a otra, cuya socialización se produce en un ámbito específico. En el caso de un diario ese ámbito de socialización tiene, por lo menos, tres zonas: la de puertas adentro del diario, donde se procesan los intereses estrictamente periodísticos que van definiendo un estilo, pero también los económicos y financieros sobre los que se sostiene la posibilidad de sobrevivencia de la empresa; la interna al campo periodístico, donde se regula la competencia con los otros medios que se presentan como alternativas en el mercado de lectores; y la de la esfera pública, en la que el diario establece un vínculo particular con los lectores potenciales y con los diferentes sectores de poder -muy especialmente con el poder político-, definiendo el perfil y las modalidades de su intervención en esa esfera.

Los diarios son protagonistas activos de esa esfera pública donde se compite por definir las orientaciones de la política estatal y, a la vez, se procesa el enfrentamiento ideológico por explicar el sentido de esas orientaciones. Una dimensión política en sentido estricto, que a menudo es ocupada por el interés particular; y una dimen- 
sión de lo político en sentido amplio, un territorio más ganado por lo ideológico y que suele dar lugar a la reflexión teórica. Las formas que asume la intervención de un medio en estas dos dimensiones de la competencia político-ideológica en la esfera pública, van definiendo su discurso periodístico; esto es, un dispositivo particular de lectura de una realidad de la que el diario es a la vez testigo y protagonista. Un diario se consolida como una institución social en la medida que ajusta ese dispositivo, con el que ofrece a los lectores una re-presentación de la realidad social en la que éstos creen percibir esa básica y secreta unidad de la realidad que la experiencia diaria ha fragmentado hasta volverla incomprensible.

El discurso periodístico revela aquí su más notable parecido de familia con el otro hijo dilecto de la modernidad, el discurso político. Parafraseando la argumentación de Claude Lefort sobre lo político, podríamos decir que la prensa, al re-presentar la realidad, ejecuta un doble movimiento, de aparición y de ocultamiento $^{2}$. Aparición, en el sentido que hace visible un cierto orden de los acontecimientos, que adquieren así un sentido; ocultamiento, en tanto la lente particular del testigo-protagonista disimula la configuración del conjunto de la realidad social. Si en lo político es la fragmentación en identidades partidarias lo que explica el movimiento de ocultamiento del modo de institución de lo social; en el campo periodístico, el discurso se define como particular a partir de cada medio. Y hay otro factor, que hace a la identidad del discurso periodístico, que refuerza este movimiento de ocultamiento: me refiero a la exigencia de dar cuenta de los acontecimientos «en caliente», cuando los mismos acaban de producirse y todavía se ignora el impacto que pueden tener para el conjunto en el que cada uno de esos acontecimientos se inscribe. Si interpretar la realidad demanda dar cuenta de su configuración general, ¿cómo lograr una lectura inteligente de una realidad que está siendo? Esa capacidad de ver históricamente la realidad, de intuir las tramas más íntimas del presente como si ya fuera pasado, que Borges ponderaba en Sarmiento, es el espejo más ambicioso del periodista, donde se encuentra con la imagen del intelectual.

Así como el discurso político les da a sus fieles una interpretación de lo social que ordena la realidad de determinada manera volviéndola más comprensible, la re-presentación de la realidad que hace la prensa día a día les ofrece a sus lectores fieles algo similar. En ese volver a presentar la realidad se articulan, de determinada

\footnotetext{
${ }^{2}$ Claude Lefort, La invención democrática, Buenos Aires, Nueva Visión, 1990.
} 
manera, diferentes acontecimientos, sugiriendo un orden y sentido con el cual el lector, desde su particularidad, se re-liga con la unidad de lo social.

Este aspecto casi religioso de la relación que los lectores establecen con su diario de cabecera es una característica fundamental de la prensa en el siglo XX que hoy ha sido, en alguna medida, puesta en cuestión por el impacto de internet y el desarrollo de las redes sociales. Prácticamente hasta las décadas finales del siglo pasado, esta relación de la prensa y los individuos que conformaban el campo de lectura periodístico, estaba pautada por el ritualismo y la fidelidad que, nada casualmente, puede asociarse al de los participantes de una identidad política con su divisa partidaria. La mayoría de los lectores potenciales en los ańos veinte, cuarenta, pero también en los sesenta, repite día a día la costumbre de mirar la realidad a través de un diario, o algunos diarios que casi siempre son los mismos. Esa operación de lectura está, a su vez, cargada de otros actos rituales, como el lugar, el horario y el recorrido particular con el que cada uno deconstruye lo que el diario ha construido como texto. Esa suma de pequeños actos, generalmente inadvertidos, que componen el rito de cada lector, y la suma de actos particulares y aislados que integran al conjunto de los lectores, tienen un punto de unidad del otro lado de la relación, del lado de la oferta. Es el diario el elemento que da unidad a ese mundo de relaciones que se constituye, precisamente, a partir de él; y si algo tan producido puede parecer natural es, precisamente, porque es el resultado de una operación exitosa, por la cual un medio periodístico ha logrado consolidarse como una institución social sellando con la mayoría de sus lectores un pacto de lectura de la realidad que procesa, generalmente de manera acrítica y por lo tanto inadvertida, creencias y sensibilidades.

Como planteaba más arriba, El Litoral completó una primera operación exitosa de institucionalización social en sus décadas fundacionales de la Argentina preperonista. Por supuesto que esta operación primera no es suficiente para explicar el lazo laico que reunirá al diario y sus lectores en las décadas siguientes, que seguramente es resultado de la capacidad del vespertino para reeditar el éxito original. Lo que sí sostenemos como una hipótesis ordenadora de nuestra argumentación, es que en esa etapa fundacional el diario construyó una tradición que recortó con cierta precisión su perfil en la ciudad y, en ésta, el campo de lectores. Aunque no suficiente, hay en esa marca de origen un factor necesario para explicar su sobrevivencia, su estilo hasta los años sesenta al menos y la frontera de inclusión/exclusión con que supo definir su protagonismo en la sociedad santafesina. 
En ese contexto conviene realizar un breve recorrido por los elementos constitutivos del clima de época marcado por las dos guerras mundiales que presidió la emergencia de esta tradición periodística.

En la Argentina de entreguerras, el horizonte para la organización de una institución periodística se constituía en la intersección de dos tipos de fenómenos: uno, más general, determinado por los cambios en la sociedad y el Estado y su impacto en el mundo de las ideas; otro, más particular, constituido en el orden de desarrollo interno del campo periodístico.

En el plano más general, el clima de época está enmarcado por las dos guerras mundiales y signado por la crisis ideológica mundial y la caída de la España republicana que adelantaba la tragedia que, inmediatamente después, de la mano del fascismo y especialmente del nazismo, pondría entre comillas a la cultura occidental. La primera guerra mundial es un verdadero parteaguas con las certidumbres político-ideológicas del siglo XIX que habían motorizado la expansión del capitalismo y la consolidación del Estado-nación como sujeto de la soberanía de cada sociedad (ya a la par de los acontecimientos, José Ingenieros denunciaba lo que llamó «el suicidio de los bárbaros» como el fin de una época; y en nuestros días, Eric Hobsbawm ha construido la sugerente imagen de un corto siglo XX que, contradiciendo los caprichos del almanaque, comenzaría precisamente con la Gran Guerra) $)^{3}$. La crisis ideológica resultante tendrá varios y diferentes recorridos en los senderos marcados por la revolución de octubre de 1917 y el crecimiento del fascismo en los países europeos. Tras la trama, era el paradigma liberal que desde el siglo anterior orientaba la relación Estado-sociedad, el que venía a ser puesto en cuestión. Otros cambios, igualmente importantes, como las transformaciones en el mundo de la producción y el consumo, confirmaban el agotamiento de esa forma estatal construyendo el espacio para la emergencia del paradigma keynesiano que presidiría la reestructuración de los Estados nacionales luego de la crisis del 30.

En el caso argentino el síndrome ideológico de entreguerras corre en paralelo con el más general de los países occidentales, con desarrollos particulares que conviene destacar por la importancia para nuestra argumentación. Sobre todo los desarrollos que giran en torno a los efectos de la constitución de la democracia electoral a partir de 1912 y la complejización del sistema político. Aunque la experiencia de

\footnotetext{
${ }^{3}$ Eric Hobsbawm, Historia del sig/o XX, Barcelona, Crítica, 1996.
} 
democratización se clausura en 1930, la constitución compulsiva de la ciudadanía política y el ensanchamiento de la participación en el sistema político, impacta en el mundo de las ideas a lo largo de todo el período de entreguerras. Si la ampliación de la ciudadanía es un dato que trasciende a la coyuntura, el problema central en la discusión político ideológica pasa por definir los significados que impone en la constitución del poder político.

A lo largo de ese debate que el revisionismo histórico trasladaría al pasado nacional, el quiebre de las certidumbres ideológicas provoca el estallido del consenso básico liberal que había acompañado el proceso de constitución y ampliación del sistema político. El punto final para el consenso liberal se confirmará en los ańos treinta, cuando los conceptos de liberalismo y democracia afirman un recorrido disociado que presidirá la emergencia de la Argentina peronista ${ }^{4}$.

Paralelamente a la tormenta que conmovía el mundo de las ideas, la sociedad argentina continuaba un desarrollo iniciado en el siglo XIX que, en los años de entreguerras, impactará directamente en el campo de la prensa escrita.

Desde mediados del siglo XIX, el proceso de invención de la Argentina y los argentinos tuvo un cauce firme en el desarrollo educativo. Los resultados del ambicioso proyecto impulsado por el Estado son conocidos, por lo que señalaremos únicamente su directa influencia en la conformación del campo periodístico. Algunas cifras hablan por sí solas: cuando la Argentina de Urquiza, Mitre y Sarmiento iniciaba la travesía de la modernización el índice de analfabetismo superaba el $70 \%$; en los años treinta del siglo XX esa cifra no alcanzaba el 7\%, y si recortamos el universo de análisis sobre las ciudades el índice cae a la mitad de esa media nacional (y estamos hablando de una población que se ha multiplicado por cuatro entre el primer censo nacional de 1869 y el tercero de 1914). Un último dato en la misma dirección: en la década del veinte se duplicó el número de alumnos encuadrados en el nivel secundario del sistema educativo.

Más allá de los matices que podría introducir un análisis cualitativo, las cifras son tan contundentes que es imposible disimular la conclusión: en los años que nos ocupan, y como resultado de la madurez del sistema educativo, se produjo una notable ampliación del mercado de lectores potenciales.

4 Tulio Halperin Donghi, La argentina y la tormenta del mundo. Ideas e ideología, 1930-1943, Buenos Aires, Siglo Veintiuno editores Argentina, 2003; Mariano Plotkin, Mañana es San Perón, Buenos Aires, Ariel, 1994. 
Los datos son igualmente sugestivos del otro lado de la relación, del lado de la oferta periodística. Alrededor de 1930 el tiraje diario de periódicos y revistas en el país en su conjunto se aproxima a los dos millones de ejemplares. Entre la oferta y la demanda, entre la producción y el consumo, el campo periodístico cambia aceleradamente en estos años. Como señala Beatriz Sarlo, «diarios y revistas responden a un nuevo público que, al mismo tiempo están produciendo. Un circuito de lectores que, también por la acción del nuevo periodismo, está cambiando y expandiéndose: se trata de una cultura que se democratiza desde el polo de la distribución y el consumo" ${ }^{5}$.

Cambios en la sociedad que amplían cuantitativa y socialmente el universo de lectores, y un nuevo periodismo que diversifica la oferta expandiendo sus temáticas hacia zonas hasta entonces ignoradas y renovando sus modalidades de tratamiento. Las novedades en el campo específico de los diarios son un núcleo fundamental de este cambio de época de la prensa.

La metodología de análisis planteada por Tim Duncan para caracterizar la evolución histórica de los diarios, recomienda la consideración especial de cuatro variables: finanzas, personal, perspectivas de sobrevivencia y estilo ${ }^{6}$. De acuerdo a las formas en que se combinan estas variables, la prensa predominante en la Argentina del siglo XIX puede caracterizarse como prensa política. Concepto que abarca a los diarios más exclusivamente facciosos, que eran puestos de combate para una de las facciones en pugna, y a los que, en los años finales del siglo, habían abandonado sus rasgos más panfletarios pero continuaban estrechamente ligados al sistema político.

La prensa característica del siglo XX, en cambio, es el diario moderno de circulación masiva. Con diario moderno se define a una institución autosuficiente, en el sentido que determina por sí misma sus formas de financiación, su personal, su futuro y su estilo. Los diarios de circulación masiva del siglo XX tienen precisamente en esa circulación, y en la publicidad que la acompaña, la condición de posibilidad de su autosuficiencia. A la vez, el diario moderno está dirigido y escrito por profesionales y no por políticos, participando en sus páginas muchos de los mejores intelectuales y escritores.

\footnotetext{
${ }^{5}$ Beatriz Sarlo, Una modernidad periférica: Buenos Aires 1920 y 1930, Buenos Aires, Nueva Visión, p. 19.

6 Tim Duncan, «La prensa política: Sud-América», op. cit.
} 
En los estudios del caso argentino de este pasaje del diario político al diario moderno, es habitual situar la transición en una época enmarcada por el surgimiento de Crítica (1913) y El Mundo (1928), dos diarios que harían época cambiando el estilo de la prensa gráfica. Ambos periódicos motorizaron una ampliación del mercado de lectores (de los «señores» a los sectores medios y populares) que es esa condición de posibilidad para la constitución de la prensa moderna.

1913-1928, este es, precisamente, el contexto de emergencia de El Litoral; un período de transición en el que se está consolidando el diario moderno. Es posible seguir esta transición en las mismas páginas de El Litoral en sus comienzos y a lo largo de la década del veinte, y apreciar un rumbo más definido en los años treinta y primera mitad de los cuarenta, cuando logrará consolidar un campo de lectores fieles lo suficientemente amplio como para garantizar su sobrevivencia con independencia del sistema político ${ }^{7}$.

Ahora bien, en ese recorrido, El Litoral fue ajustando su estilo mirándose a diario en un par nacional que, paralelamente, ofrecía otro sendero de modernización, diferente al que proponían Crítica o El Mundo. Desde fines de la primera década del siglo XX La Nación había comenzado a transitar un camino de modernización que definiría su estilo a lo largo del siglo y le aseguraría su sobrevivencia e impacto calificado en la opinión pública.

Como señala Ricardo Sidicaro, cuando Luis Mitre se hizo cargo de la dirección del diario, en 1909, se afirmó el alejamiento del matutino de la identificación directa con un partido político ${ }^{8}$. Una antigua aspiración con la que el mismo Bartolomé Mitre había decidido el paso de La Nación Argentina a La Nación a secas, pero que sin embargo no había logrado ir más allá del mero nivel del enunciado que subtitulaba al nuevo diario: tribuna de doctrina. Todavía en los primeros años del siglo XX, bajo la dirección de Emilio Mitre, el matutino porteño estaba tan comprometido en la lucha política directa que asumía sin mediaciones el discurso del Partido Republicano, que promovía a la presidencia de la República precisamente al director del periódico. A las puertas del Centenario, esa antigua aspiración de «forjar un punto de

\footnotetext{
7 Darío Macor: «La emergencia de una tradición en el periodismo santafesino», en: Edición especial de la Universidad Nacional del Litoral en el 80 aniversario del diario El Litoral, Santa Fe, agosto de 1998; y «La prensa en la esfera política en los orígenes de El Litoral», en: Revista 80 aniversario del diario El Litoral, Santa Fe, 09/08/98.

${ }^{8}$ Ricardo Sidicaro, La política mirada desde arriba, op. cit.
} 
vista colocado por encima de los conflictos partidarios» comenzó a hacerse realidad. Tomar distancia de la lucha partidaria era el camino para relacionarse mejor con el conjunto de la clase dirigente argentina. El objetivo no era alejarse de la política, sino mirar a la política desde arriba; desde arriba de los partidos, estableciendo un diálogo directo con la clase dirigente. La Nación, sería la voz de esa clase, pero también «le hablaría» en un «esfuerzo político-pedagógico» capaz de dar cuenta de los intereses más universales que podían ser oscurecidos por la lucha político-partidaria.

En ese proceso de modernización de La Nación hay un rico espejo para mirar las experiencias exitosas de transformación de muchos diarios de provincia. La imagen principal que podía encontrarse en el espejo del matutino porteńo era clara: forjar ese punto de vista que le permitiera al diario ponerse "por arriba» de la lucha política inmediata. Sólo evitando la asociación con un partido, el diario podía construir un discurso político que le fuera respetado como propio. Paradójicamente, el éxito de esta operación jerarquizaba al diario como un actor político, pero colocándolo en un lugar menos permeable a los enfrentamientos partidarios y los problemas de coyuntura.

Desde ese lugar tan prominente en el que, a la manera del intelectual, se situaba el discurso periodístico, ¿̨ómo definir el interlocutor principal en un espacio local? Si afirmamos que El Litoral construyó una tradición, entre 1918 y 1945, es porque, en ese período, desarrolló una interlocución privilegiada con una elite dirigente que en la aldeana Santa Fe de entreguerras estaba sobredimensionada. La ciudad capital de la provincia contenía en su seno a todos los poderes del Estado provincial y una de las principales Universidades del país (la Universidad Nacional del Litoral, con sedes académicas repartidas en la ciudad de Santa Fe, Rosario, Corrientes, Resistencia y Paraná); situación que le daba una fisonomía político-cultural muy particular. Esta densidad de la política y la cultura en la ciudad definieron un tipo de sociabilidad que entrelazaba la actividad política con la cultural y, entre ambas, la periodística.

El Litoral produjo la invención de su tradición re-presentando los imaginarios colectivos de ese campo de sociabilidad; que expandió desde sus páginas a un público más amplio, matrizando una opinión pública. Con la ventaja que da la mirada retrospectiva podríamos decir que esa capacidad de representar un imaginario colectivo explica, en mucho, las claves de su sobrevivencia; a pesar de los cambios que sobrevendrán a partir de 1945, cuando esa tradición político-cultural será interpelada en nombre de los sectores populares. 
III

Retomando lo expuesto hasta aquí podemos decir que a lo largo del siglo XX y muy especialmente en los ańos centrales del siglo, los medios de prensa escritos en general y el vespertino El Litoral en particular fueron protagonistas activos de la esfera pública, donde se competía por definir las orientaciones de la política estatal procesando, a la vez, el enfrentamiento ideológico por explicar el sentido de esas orientaciones. En ese protagonismo, hay una dimensión política en sentido estricto, que a menudo es ocupada por el interés particular; y una dimensión de lo político en sentido amplio, un territorio más ganado por lo ideológico, que suele dar lugar a la reflexión teórica. Las formas que asume la intervención de un medio de prensa en estas dos dimensiones de la competencia político-ideológica en la esfera pública, van definiendo su discurso periodístico; esto es, un dispositivo particular de lectura de una realidad de la que el diario es a la vez testigo y protagonista. Un diario se consolida como una institución social en la medida que ajusta ese dispositivo, con el que ofrece a los lectores una re-presentación de la realidad social en la que éstos creen percibir esa básica y secreta unidad de la realidad que la experiencia diaria ha fragmentado hasta volverla incomprensible.

En nuestra hipótesis, desde su fundación, en 1918, hasta los comienzos de la Argentina peronista, en 1945/46, El Litoral realiza una primera operación exitosa de institucionalización social; en esos años, el diario recorta con precisión su perfil en la ciudad y, en ésta, el campo de lectores. Por supuesto que lo sucedido entonces no es suficiente para explicar el lazo laico que, a lo largo de los ańos posteriores y hasta el presente, reúne al diario y sus lectores. Sin embargo, aunque no suficiente, hay en esa marca de origen un factor necesario para explicar su sobrevivencia, su estilo y sus derivas en los años subsiguientes, y la frontera de inclusión/exclusión con que fue definiendo su protagonismo en la sociedad santafesina?.

La Santa Fe de 1918 es una pequeña capital de provincia que reúne en una humana escala urbana alrededor de 80.000 habitantes. Al ritmo del siglo la renovación urbana transforma a la ciudad aldeana, aunque a diferencia de Rosario y Buenos Aires el ritmo de crecimiento poblacional no alcanza niveles de masividad como para alterar radicalmente los rasgos de la vida cotidiana. Como capital de una provincia que reconoce ya en Rosario el liderazgo económico, Santa Fe es

\footnotetext{
9 Darío Macor: «Tradición reformista y democracia», en: UNL. 90 años haciendo historia, Suplemento
} especial del diario El Litoral, Santa Fe, 17 de octubre de 2009. 
una ciudad-estado con una presencia sobredimensionada de los actores políticoinstitucionales. Esta característica del espacio urbano ayuda a explicar el desarrollo de la prensa local, su significativa tirada y la atención que desde sus columnas se presta a la cuestión política.

¿Cómo encontrar en ese medio urbano un perfil singular para un nuevo periódico? ¿Sobre qué bases definir un estilo periodístico diferenciado en el campo periodístico local?

Como ya señalamos, en esos años de la primera posguerra, en medio de una notable expansión del mercado de lectores, la prensa argentina atraviesa un período de transición, del diario político, característico del siglo XIX, al diario moderno del siglo XX. La declinación del viejo periódico faccioso del siglo XIX, ha ido cediendo su lugar a diarios que se constituyen como actores con intereses específicos independientes del sistema político. El diario moderno no rehúye a la política, pero se sitúa frente a ella como un espacio de pensamiento y no de combate, está dirigido por profesionales y no por políticos y garantiza su independencia del sistema político en la circulación masiva ${ }^{10}$.

Esta transición del diario de combate al diario de pensamiento es también un pasaje interno a cada medio periodístico. La coexistencia de lo nuevo y lo viejo caracteriza a los primeros pasos de El Litoral, que desde su fundación hasta 1945 irá procesando en sí mismo este pasaje hacia el diario moderno definiendo una matriz particular de intervención en la esfera política.

En este proceso hay dos momentos decisivos que es oportuno destacar. El primero de ellos, en torno a la reforma constitucional de 1921, cuando se define el horizonte de posibilidad para ese diario moderno; el otro, alrededor de la dictadura militar iniciada con el golpe de 1943, cuando el lugar construido por el diario en la esfera política tendrá su prueba de fuego.

En 1921, Santa Fe vive una interesante experiencia de reforma constitucional en la que El Litoral encuentra un puente de plata para su pasaje definitivo al diario moderno. Una experiencia en la cual lo político gira en torno a la cuestión constitucional, y que se reedita a comienzos de los años treinta -en la campańa

${ }^{10}$ Darío Macor: «La emergencia de una tradición en el periodismo santafesino», en: Edición especial de la Universidad Nacional del Litoral en el 80 aniversario del diario El Litoral, Santa Fe, agosto de 1998; y «La prensa en la esfera política en los orígenes de El Litoral», en: Revista 80 aniversario del diario El Litoral, Santa Fe, 09/08/98. 
electoral de 1931 y cuando el gobernador Luciano Molinas ponga en vigencia, al año siguiente, la Constitución reformada $-{ }^{11}$.

La condición de "diario moderno» exige forjar un punto de vista que le permita ponerse por arriba de la lucha política inmediata, y es evitando la asociación con un partido que el diario puede construir un discurso político que le sea reconocido como propio. La experiencia reformista del 21 provee a la prensa en transición un escenario más que apropiado para hacer política desde un lugar que a los mismos partidos les está vedado. No toda la prensa sabrá aprovecharla, claro, pero en lo que aquí interesa el vespertino local tiene su primer ejercicio importante de afinar una voz propia en la esfera pública.

Las características del enfrentamiento provocado por la reforma, suavizan las fronteras partidarias colocando el peso principal en la disputa religiosa y en la relación entre los diferentes poderes del Estado. Frente al conflicto definido en clave constitucional, el diario puede apoyar activamente la reforma sin confundirse con un partido, ya que la reforma ha dividido a las mismas organizaciones partidarias. Se puede dar, en fin, un combate político, desde un lugar que no se confunde con una facción. En esta experiencia reformista el diario bosquejará un discurso político particular, «por encima» de los partidos, que olvidará por momentos a lo largo de la década del veinte, para reencontrar con paso más seguro en los años treinta y principios de los cuarenta.

Ya en los años treinta El Litoral logra consolidar un campo de lectores fieles con amplitud suficiente como para garantizar su sobrevivencia con independencia del sistema político. El pasaje al diario moderno se va consolidando y el periódico logra constituirse como un actor político evitando la asociación estrecha con alguno de los partidos en pugna; su discurso pone el acento en los elementos comunes de la tradición democrática-liberal, en torno a la cual se tejen los argumentos partidarios de los actores colectivos con relevancia política y electoral.

\footnotetext{
${ }^{11}$ Hemos trabajado estos temas en Darío Macor, La reforma política en la encrucijada. La experiencia demoprogresista en el Estado provincial santafesino, Santa Fe, Ediciones UNL, 1993. Darío Macor, «¿Una república liberal en los años treinta? La experiencia demoprogresista en el Estado provincial santafesino», en: Waldo Ansaldi et al. (eds.), Representaciones inconclusas. Las clases, los actores y los discursos de la memoria, Buenos Aires, Biblos, 1995. Darío Macor, «Radicales, demoprogresistas y antipersonalistas: oficialismo y oposición en la Santa Fe de entreguerras», en: Boletín Americanista, № 50, Barcelona, Universitat de Barcelona, 2000.
} 
El segundo momento que señalamos es el del gobierno militar iniciado en 1943, cuando el diario pone en juego todo el capital simbólico adquirido para enfrentar a las orientaciones gubernamentales que van definiendo el rumbo del proceso político. En esos años el campo periodístico en la ciudad está más consolidado que en 1918; El Litoral ha alcanzado un tiraje diario cercano a los 40.000 ejemplares (superior al que tiene en la actualidad con una población cinco veces mayor) y el lugar de los tres o cuatro periódicos con los que competía en los primeros años está ocupado por uno, El Orden, que desde los últimos años de la década del veinte se presenta como su más serio competidor. Hay un tercer diario, La Mañana, vocero del arzobispado y de importancia entre los medios de su tipo, pero por sus características está fuera de la zona de competencia del campo periodístico.

En esta etapa del gobierno militar El Litoral se transforma en un actor político fundamental, sin perder por esto su característica de diario moderno, ya que interviene sin identificarse con un partido sino en nombre del conjunto de las fuerzas políticas que se referencian en la tradición de la democracia liberal.

En nombre de esa tradición El Litoral presentará una clara oposición ideológica a la intervención del nacionalismo integrista, en la primera etapa del gobierno militar. El accionar del nacionalismo integrista tiene su ámbito privilegiado en el campo educativo, siendo su desarrollo más destacado la intervención de Jordán Bruno Genta en el Universidad Nacional del Litoral. La brutal gestión de Genta está acompañada por procesos afines en el control de la educación provincial (José María Rosa) y, más puntualmente, en la dirección del Colegio Nacional (Vicente Fidel López). El exitoso protagonismo del diario frente al nacionalismo, le permite afinar su discurso y ganar legitimidad en la representación que ejerce de ese conglomerado político multipartidario y también cultural que se define en su oposición al gobierno militar ${ }^{12}$.

\footnotetext{
${ }^{12}$ Ver nuestro, «Un horizonte ideológico para el golpe militar de 1943. La intervención a la Universidad Nacional del Litoral». Ponencia presentada en la V Jornadas Interescuelas Departamentos de Historia y Primeras rioplatenses de Historia, Montevideo, Uruguay, 1995; y «Del nacionalismo integrista al peronismo. El ensayo nacionalista en Santa Fe en los orígenes del peronismo» en: Darío Macor y Eduardo Iglesias, El peronismo antes del peronismo. Memoria e historia en los orígenes del peronismo santafesino, Santa Fe, Ediciones UNL, 1997.
} 
Desde ese sitial alcanzado el diario sostendrá una dura polémica con los promotores de las decisivas jornadas de movilización de masas en torno al 17 y 18 de octubre. El resultado de este enfrentamiento es más difícil de dilucidar por las características del mismo ${ }^{13}$.

En esos días el protagonismo político del diario llega a su punto culminante y todo el lugar de la oposición al peronismo emergente parece estar ocupado por su voz. Tal vez el caso más sobresaliente esté dado por la discusión pública sostenida con Leandro Meiners, ministro de gobierno del ejecutivo provincial, de tradición radical y quien será en 1946 candidato a la gobernación en representación del peronismo. Esta discusión entre «el político» del gobierno militar provincial y el diario es rica en matices, ya que lo que está en discusión es el contenido de un concepto que dividirá en dos a la Argentina: el concepto de democracia. Si Meiners, acentuando una veta arraigada en la tradición yrigoyenista, inclina el concepto sobre el aspecto que lo remite exclusivamente a la ciudadanía social, tanto como para separarlo de las tradiciones del liberalismo; El Litoral, de acuerdo a la tradición política en que ha construido su identidad periodística, insiste en el carácter inescindible de democracia y liberalismo.

Tanto en el enfrentamiento con el nacionalismo como con Meiners, el lugar ocupado por el diario es de una relevancia política notable, y en ambos casos habla desde una tradición política que trasciende a lo partidario y que ha hecho suya «por afuera» del sistema político-partidario.

\section{IV}

El triunfo del peronismo en las elecciones de 1946 daría lugar rápidamente a una nueva Argentina, consolidando rasgos ya insinuados en los años del gobierno militar. En esa nueva Argentina, que se extendería más allá de los diez años de gobierno peronista, el lugar de la prensa y del diario El Litoral sería bien diferente al de la primera mitad del siglo, no sólo por los cambios en los medios de comunicación audiovisuales que complejizarían el campo comunicacional paso a paso, sino por las novedades que vinieron de la mano del peronismo, dando lugar a un

13 Un análisis detallado de los acontecimientos de octubre de 1945 en: Darío Macor y Susana Piazzesi, «Las jornadas de octubre de 1945. El caos de la ciudad de Santa Fe», en: Boletín del FEPAl, segundo semestre, 1991. 
sistema político imposibilitado de alcanzar los consensos básicos entre las partes integrantes que, por el contrario, se niegan entre sí construyendo la condición de posibilidad para la radicalización del enfrentamiento, la militarización de la política y el abandono de toda mesura, que encontrará un trágico punto de llegada en la última dictadura militar de 1976.

Los diez ańos de la experiencia peronista serán una especie de "gran demora» para El Litoral. Ubicado en el campo de oposición incorregible, el vespertino santafesino sufriría la dureza del control oficialista: desde la clausura temporaria, generalmente de pocos días, hasta la amenaza más temida del racionamiento del papel que el gobierno usaba con la más absoluta arbitrariedad.

Frente a la embestida gubernamental el diario responde con la autocensura y lo que podríamos llamar el «encierro parroquiano». Así, mientras se esfuerza por eludir los temas políticos nacionales que pueden traerle conflictos, o los atiende con la mera reproducción de la información proveniente de las agencias gubernamentales, crece la dedicación sobre nuevos temas, como los deportivos y las cuestiones locales de la ciudad capital y la región centro-norte de la provincia ${ }^{14}$.

Con el golpe de 1955 se abre una nueva etapa que, contra las ingenuas creencias de los que habían vivido la década peronista bajo el signo de la opresión, no significaría un retorno a la Argentina anterior al 43 sino el ingreso a una nueva sociedad cargada de ambigüedades y contradicciones, entre la inestabilidad política permanente, el aumento de la conflictividad social, la modernización económica, social y cultural que caracteriza a los «años sesenta», y el crecimiento del poder militar ${ }^{15}$.

Un breve pero intenso período que, en los límites de esta ponencia, convenimos en cerrar en 1966, cuando los comienzos del onganiato introducen a la Argentina en la etapa de las nuevas dictaduras militares del cono sur y el desarrollo del Estado Burocrático Autoritario ${ }^{16}$.

Como hicimos para el período anterior, aquí también podemos destacar dos o tres hitos claves que nos permiten dar cuenta de la evolución del diario en estos diez años. Por un lado, desde el mismo momento del golpe militar, la cuestión peronista, el qué hacer frente al peronismo, aparece como un tema decisivo para la definición política de la hora. La aceptación de las medidas del gobierno mili-

\footnotetext{
14 La columna editorial del diario es un claro ejemplo.

15 Ver entre otros: Beatriz Sarlo, La batalla de las ideas, Buenos Aires, Ariel, 2001.

16 Guillermo O’Donnell. El Estado burocrático autoritario 1966-1973, Ediciones de Belgrano, 1982.
} 
tar que llevan a la proscripción y represión del peronismo enfrentan a El Litoral con dos dilemas nada menores para quien quiere volver a enarbolar la tradición liberal democrática como el paradigma desde el cual mirar la realidad y ordenarla para sus lectores: la violencia política, en especial la represión estatal; y el lugar de la democracia en un sistema que se organiza en su nombre pero sobre la base de la exclusión del partido mayoritario. Ambos temas atraviesan todo el período, aunque tiene momentos álgidos, como los fusilamientos de León Suárez durante la presidencia militar de Aramburu, o cuando el frondicismo endurece, con la aplicación del Plan CONINTES, su política represiva frente a la protesta obrera impulsada por la resistencia peronista ${ }^{17}$.

En paralelo, el enfoque que El Litoral adopta frente a la cuestión literaria o, más en general, cultural se transforma en un hito o tema que ilumina bien las ambigüedades que ganan al diario en estos años y terminan por definir un giro conservador.

En los años de Frondizi y de Illia El Litoral, no fue ajeno a la modernización cultural que renovaba a las Universidades públicas y al país en general. Como buen diario de provincia, el dilema principal giraba en torno a las respuestas posibles para escapar a la cultura parroquiana, el provincianismo, que habían sido un buen refugio en la época peronista y se presentaban ahora, frente la modernización de los sesenta, como una dura limitación.

Para dar cuenta de este problema que, repetimos, atraviesa todo el período, tenemos un ejemplo más que ilustrativo en torno al suplemento cultural del diario: un episodio, con epicentro en 1959, en torno a la página literaria ${ }^{18}$.

En los años peronistas, El Litoral atendía a la cuestión cultural desde lo local, predominantemente de la ciudad pero también de los pueblos de la región a los que llegaba en su distribución. En la nueva etapa, la renovación cultural llevaba a atender lo que estaba sucediendo en el plano nacional y a incorporar colaboradores capaces de dar cuenta por sí mismos de esa renovación, que sería uno de los distintivos más importante de esos años. Así, bajo la dirección del poeta local Hugo Gola, y bajo la sombra protectora de Juan L. Ortiz, la página literaria, sumaba talentos como

17 Daniel James, Resistencia e integración. El peronismo y la clase obrera argentina 1946-1976, Buenos Aires, Sudamericana, 1990.

${ }^{18}$ La página literaria, formaba parte del cuerpo central del diario de los días domingos en la página 4. 
Juan José Saer ${ }^{19}$, por entonces haciendo los primeros tramos de una carrera literaria consagratoria; Juan Carlos Portantiero que aún dudaba si la Sociología merecía el abandono de la escritura literaria para la que estaba particularmente dotado ${ }^{20}$; y otros escritores como, Nicolás Guillén, Aldo Oliva, Juan José Sebreli...21.

El ilustrativo episodio de 1959 tuvo como eje la publicación de un cuento de Saer, Solas ${ }^{22}$, (incluido luego en En la zona). La publicación provocó un escándalo en la sociedad cultural santafesina, fogoneado especialmente por muchos de los integrantes del campo cultural local, ahora menos considerados por el diario y temerosos frente al giro cultural que ganaba a sus páginas, y sectores de la iglesia católica siempre celosos de la moral y las buenas costumbres interpeladas por las insinuaciones lésbica del cuento saeriano.

El conflicto tiene una resolución drástica que marcará a fuego al diario, con el cierre del suplemento y el abandono de las veleidades de modernización cultural que iban de la mano de Gola y Saer. Gracias a Sergio Delgado tenemos la voz de Saer, años después en una charla-entrevista con él, explicando esa resolución que terminó con la experiencia renovadora ${ }^{23}$. «En realidad (dice Saer) el escándalo de Solas fue la gota que colmó el vaso. Ya antes Caputto nos había llamado a Gola, a Víttori y a mí, y nos dijo esta frase histórica: Miren muchachos: lo que ustedes hacen está muy bien, pero Santa Fe es una ciudad mediocre, El Litoral un diario mediocre, y por lo tanto su página literaria tiene que ser mediocre. Ante esa lógica de hierro (termina Saer) no pude decir nada ${ }^{24}$.

El considerar a la ciudad de Santa Fe como una sociedad mediocre releva a la nueva dirección del diario (descendientes de los Caputto y Víttori fundadores) del compromiso de apostar a un emprendimiento periodístico ambicioso, que sin embargo resultaba imprescindible si se trataba de volver a encabezar, como en los años pre-peronistas, una opinión pública ahora menos sumisa al relato periodístico.

${ }^{19}$ El Litoral, 11/03/1956, 02/09/1956, 14/10/1956, 31/12/1959, 10/03/1957, 17/11/1957, 24/02/1958, 28/09/1958, 15/02/1959.

20 Juan Carlos Portantiero, «Anotaciones sobre nuestra literatura y sus problemas», El Litoral, 01/02/1959.

${ }^{21}$ El Litoral, 21/12/1958, 01/03/1959, 08/03/1959.

22 El Litoral, 26/04/1959.

${ }^{23}$ Conversaciones con Sergio Delgado -escritor santafesino actualmente radicado en Francia- quien editó la «poesía inédita» de Juan José Saer.

${ }^{24}$ Ibíd. 
En 1918, el fundador de El Litoral, Salvador Caputto, un hombre del radicalismo con diálogos con el anarquismo tan originales como los que permitía el campo literario argentino de entonces, veía a la ciudad de Santa Fe como un espacio moderno que requería de un medio como el que él creaba para acompañar un proceso de transformación socio cultural cuya positividad no era necesario destacar por obvia. Medio siglo después, su descendiente, nos devuelve una mirada cargada de pesimismo: la Santa Fe de la armonía entre cultura y política ha dado lugar a una ciudad mediocre que, como tal, no puede sino tener un diario mediocre. Dura mirada que no refleja tanto el objeto ciudad utilizado como principal referencia, sino el proceso de conservadorismo que ha ganado a la clase dirigente local (que es parte de un fenómeno nacional de la elite dirigente) frente a las novedades sociales y políticas que reformulan la Argentina posperonista.

\section{V}

Como ya señalamos la exitosa operación de modernización de El Litoral en la Argentina pre-peronista requirió construir su identidad a partir de algunos contenidos constitutivos del campo político en su conjunto, dando cuenta de lo que estaba por encima de las partes. En esa operación, el diario ordena la sociedad, sus jerarquías internas, y define lo político, señalando y explicando el sentido de lo que es presentado como piso común. Establecidos los ejes de su discurso, el diario hace política desde lo pedagógico, es decir, se presenta en el universo de lo político como el custodio de valores comunes, y cuya responsabilidad es inculcar e imponer la defensa de éstos, sobre todo en los momentos que pueden ser afectados por la competencia partidaria.

Esta operación, siempre difícil, podía resultar relativamente sencilla en la Argentina pre-peronista porque los enfrentamientos políticos, aunque duros, no habían mellado un cierto consenso básico sobre las bondades de la democracia liberal. El paradigma de la democracia liberal homogeneizaba el campo político, lo que se reforzaba en sociedades como la santafesina donde la mayoría de la dirigencia política participaba de rutinas socio-culturales afines.

Es en ese paradigma de la democracia liberal donde se refugia El Litoral. Asociando el concepto de liberalismo con el de democracia, pone un acento especial en las modalidades republicanas de organización del poder político. No sin tropiezos, 
desde su fundación el diario ha ido forjando en esa sintonía un punto de vista que le permitiera ponerse "por arriba» de la lucha política inmediata.

Que esta operación fue exitosa lo demuestra el rol asumido en el conflictivo ańo 45. Si el diario ocupa entonces un lugar tan relevante, es porque la alternativa emergente del seno mismo del gobierno militar viene a poner en cuestión no a un partido sino a la tradición republicana y el paradigma de la democracia liberal. Nadie mejor situado para hablar en nombre del campo político tradicional, entonces, que quien participa en él como custodio de esos valores comunes y coloca su lugar de enunciación por arriba del universo político partidario.

Sin embargo, en el enfrentamiento con el peronismo emergente este lugar alcanzado por el diario va a ser puesto en cuestión desde un ángulo inesperado. No se trata de una derrota política que lo desplaza de su lugar de enunciación como primero entre pares del campo liberal-democrático; es la idea misma de la existencia de este campo homogéneo lo que el peronismo introduce como novedad, produciendo un corrimiento cuyo significado político y cultural no sería advertido inmediatamente. El tajo que dividió en dos a la sociedad, confinó al diario a la mera representación de una parcialidad, a vocero de una de las partes en las que, binariamente, quedaba dividido el nuevo campo que se conformaba con la emergencia del peronismo.

El resultado de esa coyuntura histórica es conocido y definirá el desarrollo político de la Argentina por décadas. Desde entonces nada será igual, fundamentalmente porque la Argentina que nacía en esos años estaría caracterizada por la ausencia de un consenso político básico. ¿Cómo situarse entonces por encima de la política si no hay un paradigma aceptado por todos para definir el sentido de lo político? Disociados en la práctica efectiva los conceptos de democracia y liberalismo, aquél se confunde con el populismo y éste con el conservadorismo dejando un espacio vacante de más de medio siglo en el que languidecerá la tradición republicana.

Desde entonces, El Litoral ha acentuado sus rasgos más conservadores y provincianos, y en un giro que es común a la prensa escrita en general, ha sobredimensionado a la "opinión pública» como el principal dispositivo de legitimación de su intervención en la esfera política. Un actor virtual, por cierto, que refuerza la imagen de externalidad en la representación cotidiana de la realidad y les permite -a los diarios y a los lectores- construir la imagen no menos virtual de una sociedad homogénea. 